\title{
Prevalence of metabolic syndrome and health-related quality of life in war-related bilateral lower limb amputees
}

Hanieh-Sadat Ejtahed ${ }^{1}$, Mohammad-Reza Soroush ${ }^{2}$, Shirin Hasani-Ranjbar ${ }^{1,3}$, Pooneh Angoorani ${ }^{3}$, Batool Mousavi $^{4 *}$, Mehdi Masumi ${ }^{2}$, Farhad Edjtehadi ${ }^{5}$ and Mahmood Soveid ${ }^{5}$

\begin{abstract}
Background: Lower limb amputation is correlated with considerable impairments in health-related quality of life (HRQOL) in veterans. The aim of this study is to determine the prevalence of metabolic syndrome (MetS) in veterans with bilateral lower limb amputation and to identify its association with HRQOL.

Methods: This cross-sectional study was conducted on 235 Iranian male veterans with bilateral lower limb amputation. Demographics, anthropometrics, and biochemical measurements were assessed and MetS was defined by National Cholesterol Education Program Adult Treatment Panel III definition. HRQOL was assessed using the 36-item Short Form Health Survey (SF-36) questionnaire which measures eight health-related domains. The scores were compared between two groups of bilateral lower limb Amputees who have diagnosed with and without MetS.

Results: The response rate was $40.7 \%$ and the mean age of the amputees was 52.05 years. $62.1 \%$ of participants were suffering from MetS (95\% Cl: 55.9\%-68.4\%). Patients with MetS were observed to have higher weight, waist and hip circumferences, FBS, TG, LDL and liver enzymes concentrations $(P<0.05)$. Although scores on all 8 subscales of SF-36 were low, no significant difference was observed in HRQOL scores between amputees with and without MetS. Moreover, the risk of MetS was not significantly different across subjects in the highest compared to the lowest quartile category of HRQOL scores.

Conclusions: Prevalence of MetS in veterans with bilateral lower limb amputation was higher and their HRQOL was lower compared to general population. Some strategies are needed to reduce the risk of cardiovascular diseases among this susceptible population.
\end{abstract}

Keywords: Metabolic syndrome, Quality of life, Lower limb amputees, Veterans

\section{Background}

War has a far-reaching impact on the health and wellbeing of the soldiers, war veterans, victims and even on the population as a whole [1]. Imposed Iran-Iraq war was one of the longest military conflicts in the 20th century. The health-related effects of war on soldiers and veterans including amputation have been widely studied [2-5]. The most common cause of amputation in Iranian veterans in

\footnotetext{
* Correspondence: mousavi.b@gmail.com

${ }^{4}$ Prevention Department, Janbazan Medical and Engineering Research Center (JMERC), No.17, Farokh st, Moghadas Ardebili st, Yaman st, Chamran Ave, Tehran, Iran

Full list of author information is available at the end of the article
}

Iran-Iraq war is land mine accovunting for $89.7 \%$ of injuries, and lower limb amputation is the most common type of amputation [6] which is associated with considerable morbidity, mortality, and disability [7].

Since lower limb amputees have major progressive disabilities in their daily activities and social performance [8], it may affect the individual' weight and subsequently leads to metabolic syndrome and cardiovascular diseases $[9,10]$. Metabolic syndrome is defined as a pattern of metabolic disturbances including central obesity, insulin resistance and hyperglycemia, dyslipidemia, and hypertension. The third report of the National Cholesterol Education Program Adult Treatment Panel III (ATP III) 
recognized the metabolic syndrome as a secondary target of risk-reduction therapy [11]. On the other hand, the negative effect of MetS on Health-Related Quality of life (HRQOL) have been reffered to in some studies $[12,13]$. However, the quality of life status in veterans with or without metabolic syndrome has not been explored completely among the so called population. Thus, we decided to identify the prevalence of metabolic syndrome in veterans and to explore the relationship between the quality of life and factors associated with metabolic syndrome in veterans with bilateral lower amputation.

\section{Methods}

The ethics committee of Janbazan Medical and Engineering Research Center (JMERC) approved the study (No. 85-E-P-102, date of approval: November 29, 2006) and written informed consents were obtained from all veterans.

This was a cross-sectional study which was conducted on 235 male veterans with bilateral lower limb amputation who were supported by the Veterans and Martyrs Affairs Foundation (VMAF). This foundation holds comprehensive data of all civilians and veterans of the Iran-Iraq War, who are suffering from clinical health problems and disabilities [14]. Out of 578 veterans with bilateral lower limb amputation supported by the VMAF, 235 veterans participated in this study (response rate was 40.7\%). Demographic data including age, level of education, employment status, marital status, and clinical data including level of amputation, sport activity, cause and time of amputation were collected using a questionnaire. Anthropometric measurements including weight, waist and hip circumferences and blood pressure were measured by trained physicians. Weight was measured to the nearest $100 \mathrm{~g}$ using special digital scales for amputees, in sitting position while the participants were minimally clothed, without prosthesis. Waist circumference (WC) was measured at the point of noticeable waist narrowing, hip circumference $(\mathrm{HC})$, measured at the widest girth of the hip and waist-to-hip ratio (WHR) more than 0.9 was considered as abdominal obesity [15]. Blood pressure was measured two times after 15 min resting in the seated position by a standard mercury sphygmomanometer of the right arm of the subjects. The mean of 2 measurements was considered as the participant's blood pressure. For biochemical measurements, blood samples were taken from the participants after 12-14 h fasting. Enzymatic colorimetric tests were used for measuring fasting blood glucose (FBG), total cholesterol (TC) and triglyceride (TG) levels. High-density lipoprotein cholesterol (HDL-C) was measured after the precipitation of the apolipoprotein Bcontaining lipoproteins with phosphotungstic acid. Lowdensity lipoprotein cholesterol (LDL-C) was calculated from serum TC, TG, and HDL-C using the Friedwald formula [16]. Serum glutamate oxaloacetate transaminase (SGOT) and serum glutamate pyruvate transaminase (SGPT) were analyzed by enzymatic calorimetric methods. Creatinine (Cr) and blood urea nitrogen (BUN) levels were also measured by automated biochemistry machine aaccording to the standard procedure of Pars azmoon kits.

\section{Metabolic syndrome}

The presence of MetS was determined in participants in accordance with the definition provided by the National Cholesterol Education Program-Adult Treatment Panel III (ATP III). According to the ATP III definition, MetS was defined as having 3 or more of the following metabolic abnormalities: (1) high FBG $\geq 100 \mathrm{mg} / \mathrm{dl}$ or use of medication, (2) high $\mathrm{TG} \geq 150 \mathrm{mg} / \mathrm{dl}$ or use of medication, (3) low HDL-C $<40 \mathrm{mg} / \mathrm{dl}$, (4) elevated blood pressure $\geq 130 / 85 \mathrm{mmHg}$ or use of medication and (5) High WC $\geq 95 \mathrm{~cm}[17,18]$.

\section{Health related quality of Life}

Health related quality of life (HRQOL) was assessed using the 36-item generic questionnaire (SF-36) which is used for the general population or for different patient groups. The questionnaire contains 36 items for evaluating 8 health-related domains, including physical function $(\mathrm{PF})$, physical role $(\mathrm{PR})$, general health $(\mathrm{GH})$, bodily pain (BP), vitality (VI), social functioning (SF), emotional role (RE), and mental health (MH) and also two summary scales, Physical Component Summary (PCS) and Mental Component Summary (MCS). The scores were transformed to a range of 0 (worst HRQOL) to 100 (best HRQOL). The eight scales are hypothesized to form two distinct clusters)physical and mental health(. The scales including Physical Functioning, Role Physical, and Bodily Pain were founded to be most highly correlated with the physical component and contributed most to the scoring of the Physical Component Summary (PCS) measure. As well, Mental Health, Role Emotional, and Social Functioning scales were mostly correlated with the mental component and contributed most to the scoring of the Mental Component Summary (MCS). These findings demonstrated that those scales putting more emphasis on the physical component are most responsive to treatments that change physical morbidity. In contrast, those scales focusing on the mental component responded the most to therapies that targeted mental health $[19,20]$.

The psychometric properties of the Iranian version of the SF-36 examined in a previous study indicated that the internal consistency (to test reliability) for all eight SF-36 scales met the minimum reliability standard, the Cronbach's $\alpha$ coefficients ranging from 0.77 to 0.90 with the exception of the vitality scale (alpha $=0.65$ ). The known groups comparison showed that in all scales the SF-36 
discriminated between men and women, and old and young respondents as anticipated (all $P$ values less than $0.05)$. Convergent validity (to test scaling assumptions) using each item correlation with its hypothesized scale showed satisfactory results (all correlation above 0.40 ranging from 0.58 to 0.95 ). Factor analysis identified two principal components that jointly accounted for $65.9 \%$ of the variance [20].

\section{Statistical analysis}

All statistical analyses were conducted using SPSS (Version 16.0; SPSS Inc, Chicago, IL). $P$ values $<0.05$ was considered significant. Continuous variables are reported as the mean \pm standard deviation and categorical variables as percentages. Participant demographic characteristics, anthropometric and biochemical measurements were compared between two groups of bilateral lower limb amputees with and without MetS using the Independent Samples T-Test or Mann-Whitney $U$ test or the Chi-square test. The HRQOL scores were compared between two groups of bilateral lower limb amputees with and without MetS using the Independent Samples $T$-Test or Mann-Whitney $U$ test. The HRQOL scores were categorized by using quartile cutoffs. Incident odds ratio (OR) with 95\% confidence intervals $(\mathrm{CI})$ were obtained using multivariable logistic regression. Logistic regression was used to assess the relationship of HRQOL scores and risk of MetS. In multivariable models, we adjusted for age, weight without prosthesis, physical activity, smoking status and additional war-related injuries.

\section{Results}

The mean age of the amputees was $52 \pm 6.05$ years and the mean age at the time of amputations was about 31.5 years. In $97.4 \%$ of subjects bullet was the cause of amputations and $62.6 \%$ of amputees had other injuries including upper extremity, visceral, face and head injuries. The majority of the participants (97.9\%) were married. $62.1 \%$ of amputees were suffering from MetS (95\% CI: 55.9\%-68.4\%). Demographic characteristics of amputees classified as having MetS or not are summarized in Table 1. No significant difference was observed in demographic variables, between subjects with and without MetS except for age and duration of right and left legs amputations. The participants with MetS were older (mean age: $52.7 \pm 5.5$ vs. $51.0 \pm$ 6.6 years; $P<0.05$ ) with longer duration of right and left legs amputations $(32.1 \pm 3.4$ vs. $30.8 \pm 4.1 ; P<0.01$ and $32.1 \pm 3.4$ vs. $30.6 \pm 4.4 ; P<0.005$, respectively). As illustrated in Table 2, the mean weight, waist and hip circumferences, systolic and diastolic blood pressure, triglyceride, HDL and LDL cholesterol and liver enzymes concentrations (SGOT and SGPT) were significantly higher in the amputees with MetS compared to subjects without MetS $(P<0.05)$. HRQOL scores were compared in two groups of
Table 1 Demographic characteristics in bilateral lower limb amputees according to having MetS or not

\begin{tabular}{llll}
\hline & $\begin{array}{l}\text { Amputees } \\
\text { without MetS } \\
(n=89)\end{array}$ & $\begin{array}{l}\text { Amputees } \\
\text { with MetS } \\
(n=146)\end{array}$ & P-value \\
\hline Age (years) & $51.0 \pm 6.6$ & $52.7 \pm 5.5$ & 0.048 \\
$\begin{array}{l}\text { Duration of right leg } \\
\text { amputation (years) }\end{array}$ & $30.8 \pm 4.1$ & $32.1 \pm 3.4$ & 0.006 \\
$\begin{array}{l}\text { Duration of left leg } \\
\text { amputation (years) }\end{array}$ & $30.6 \pm 4.4$ & $32.1 \pm 3.4$ & 0.004 \\
$\begin{array}{l}\text { Educational status } \\
\quad<12 \text { years (\%) }\end{array}$ & 41.6 & & 0.586 \\
$\quad \geq 12$ years (\%) & 58.4 & 45.2 & \\
$\begin{array}{l}\text { Married (\%) } \\
\text { Having sport activity (\%) }\end{array}$ & 97.8 & 54.8 & \\
$\begin{array}{l}\text { Smokers (\%) } \\
\text { Cause of amputation }\end{array}$ & 34.8 & 97.9 & 0.627 \\
$\quad$ Bullet (\%) & 98.9 & 0.234 \\
Having additional war- \\
related injuries (\%)
\end{tabular}

Data represented as mean \pm SD or frequency (\%)

amputees are presented in Table 3. We observed no significant difference in 8 health-related domains and also two summary scales of HRQOL between subjects with and those without MetS. OR and 95\% CI of MetS in each quartile category of HRQOL scores are shown in Table 4. The risk of MetS was not significantly different across subjects in the highest compared to the lowest quartile category of HRQOL scores even after adjustment for age, weight without prosthesis, physical activity, smoking status and additional war-related injuries.

\section{Discussion}

In this study we evaluated the prevalence of MetS, as an important public health problem, among Iranian male veterans with bilateral lower amputation and compared the health related quality of life in them according to having MetS or not.

Our cross-sectional findings showed a higher prevalence of MetS in veterans with bilateral lower amputations in comparison with general populations. In our study, the prevalence of MetS among amputees was $62.1 \%$ (95\% CI: $55.9 \%-68.4 \%$ ) while, according to the definition of US National Cholesterol Education Program Adult Treatment Panel III (NCEP ATP III), 23.7\% of the world wide general populations [21] and about $27 \%$ of Iranian populations [22] suffer from MetS. Patients with lower limb amputations appear to be two times more in risk of developing of metabolic disorders including obesity, hypertension, hyperlipidemia, and hyperinsulinemia [23, 24]. Moreover, high prevalence of metabolic syndrome among patients with lower limb 
Table 2 Comparison of the anthropometric and biochemical measurements in bilateral lower limb amputees according to having MetS or not

\begin{tabular}{|c|c|c|c|}
\hline & $\begin{array}{l}\text { Amputees } \\
\text { without MetS } \\
(n=89)\end{array}$ & $\begin{array}{l}\text { Amputees } \\
\text { with MetS } \\
(n=146)\end{array}$ & $P$-value \\
\hline $\begin{array}{l}\text { Weight without } \\
\text { prosthesis }(\mathrm{kg})^{\mathrm{a}}\end{array}$ & $67.6 \pm 13.1$ & $76.4 \pm 13.0$ & $<0.001$ \\
\hline $\begin{array}{l}\text { Waist circumference } \\
(\mathrm{cm})^{\mathrm{a}}\end{array}$ & $95.3 \pm 10.7$ & $107.1 \pm 11.3$ & $<0.001$ \\
\hline $\begin{array}{l}\text { Hip circumference } \\
(\mathrm{cm})^{\mathrm{a}}\end{array}$ & $98.8 \pm 10.9$ & $108.7 \pm 11.6$ & $<0.001$ \\
\hline Waist to hip ratio $(\mathrm{cm})^{a}$ & $0.97 \pm 0.1$ & $0.99 \pm 0.1$ & 0.037 \\
\hline $\begin{array}{l}\text { Systolic blood pressure } \\
(\mathrm{mmHg})^{\mathrm{a}}\end{array}$ & $120.4 \pm 15.2$ & $132.9 \pm 22.4$ & $<0.001$ \\
\hline $\begin{array}{l}\text { Diastolic blood } \\
\text { pressure }(\mathrm{mmHg})^{\text {a }}\end{array}$ & $77.3 \pm 11.3$ & $91.5 \pm 61.3$ & 0.032 \\
\hline $\begin{array}{l}\text { Fasting blood sugar } \\
(\mathrm{mg} / \mathrm{dl})^{\mathrm{a}}\end{array}$ & $88.2 \pm 16.6$ & $112.4 \pm 47.6$ & $<0.001$ \\
\hline Creatinine $(\mathrm{mg} / \mathrm{dl})^{\mathrm{a}}$ & $0.9 \pm 0.7$ & $0.8 \pm 0.2$ & 0.422 \\
\hline $\begin{array}{l}\text { Blood urea nitrogen } \\
(\mathrm{mg} / \mathrm{dl})^{\mathrm{b}}\end{array}$ & $18.0(11.0-27.0)$ & $17.0(12.0-27.0)$ & 0.836 \\
\hline Triglyceride $(\mathrm{mg} / \mathrm{dl})^{\mathrm{b}}$ & $132.0(95.5-208.0)$ & $214.0(153.5-275.5)$ & $<0.001$ \\
\hline $\begin{array}{l}\text { Total cholesterol } \\
(\mathrm{mg} / \mathrm{dll})^{\mathrm{a}}\end{array}$ & $191.8 \pm 40.5$ & $202.1 \pm 50.8$ & 0.109 \\
\hline $\begin{array}{l}\text { LDL- cholesterol } \\
(\mathrm{mg} / \mathrm{dl})^{\mathrm{a}}\end{array}$ & $115.8 \pm 36.1$ & $128.1 \pm 46.8$ & 0.042 \\
\hline $\begin{array}{l}\mathrm{HDL} \text { - cholesterol } \\
(\mathrm{mg} / \mathrm{dll})^{\mathrm{a}}\end{array}$ & $45.4 \pm 19.2$ & $36.2 \pm 8.3$ & $<0.001$ \\
\hline $\begin{array}{l}\text { Serum glutamic- } \\
\text { oxaloacetic transaminase } \\
(\mathrm{mg} / \mathrm{dl})^{\mathrm{b}}\end{array}$ & $24.0(17.0-28.0)$ & $26.0(19.0-33.0)$ & 0.028 \\
\hline $\begin{array}{l}\text { Serum glutamic-pyruvic } \\
\text { transaminase }(\mathrm{mg} / \mathrm{dl})^{\mathrm{b}}\end{array}$ & $24.0(15.0-37.5)$ & $31.0(21.0-43.0)$ & 0.003 \\
\hline
\end{tabular}

Data represented as mean $\pm \mathrm{SD}^{\mathrm{a}}$ or median (Quartiles $\left.25-75\right)^{\mathrm{b}}$

problems is reported. In studies conducted on patients with critical lower limb ischemia (CLI) and peripheral arterial disease (PAD), the prevalence of MetS was reported $52 \%$ and $63 \%$, respectively $[25,26]$. Peles et al. compared the insulin resistance between lower limb amputees and healthy controls with similar age, body mass index, blood pressure and plasma lipid levels. Amputees were found to have significantly higher fasting plasma insulin levels and insulin response to oral glucose with similar plasma glucose levels [27]. Modan et al. also showed increased levels of insulin in amputees compared to healthy controls after adjustment for age, smoking, physical activity, body mass index, mean arterial blood pressure and cholesterol [28]. Rose et al. in a study showed that veterans with bilateral above-knee amputations had significantly higher blood pressure, mean body fat content, weight and insulin levels compared to age matched unilateral below-elbow amputees [9]. These results confirm our findings indicating that high prevalence
Table 3 Comparison of the HRQOL scores in bilateral lower limb amputees according to having MetS or not

\begin{tabular}{|c|c|c|c|}
\hline & $\begin{array}{l}\text { Amputees } \\
\text { without MetS } \\
(n=89)\end{array}$ & $\begin{array}{l}\text { Amputees } \\
\text { with MetS } \\
(n=146)\end{array}$ & $P$-value \\
\hline $\begin{array}{l}\text { Physical } \\
\text { Functioning }\end{array}$ & $53.4 \pm 24.4$ & $54.9 \pm 24.5$ & 0.667 \\
\hline General Health ${ }^{a}$ & $55.3 \pm 27.1$ & $56.3 \pm 26.8$ & 0.784 \\
\hline Vitality $^{a}$ & $65.3 \pm 25.0$ & $64.4 \pm 21.5$ & 0.777 \\
\hline Mental Health ${ }^{a}$ & $63.5 \pm 27.0$ & $65.4 \pm 24.1$ & 0.585 \\
\hline Role-Physical $^{\mathrm{b}}$ & $36.4(36.4-75.0)$ & $36.4(36.4-75.0)$ & 0.664 \\
\hline Bodily Pain ${ }^{b}$ & $42.6(22.0-61.0)$ & $42.6(32.0-66.0)$ & 0.371 \\
\hline Social Functioning ${ }^{b}$ & $75.0(56.0-100.0)$ & $64.2(50.0-87.5)$ & 0.549 \\
\hline Role-Emotional $^{\mathrm{b}}$ & $43.7(43.7-100.0)$ & $43.7(43.7-100.0)$ & 0.564 \\
\hline $\begin{array}{l}\text { Physical Component } \\
\text { Scale }^{a}\end{array}$ & $46.5 \pm 24.5$ & $47.8 \pm 22.1$ & 0.681 \\
\hline $\begin{array}{l}\text { Mental Component } \\
\text { Scale }^{a}\end{array}$ & $60.7 \pm 27.8$ & $59.7 \pm 25.0$ & 0.777 \\
\hline
\end{tabular}

Data represented as mean $\pm \mathrm{SD}^{\mathrm{a}}$ or median (Quartiles $\left.25-75\right)^{\mathrm{b}}$

of MetS in amputees. There are so many factors that increase the risk of MetS in the general population, such as genetic factors, sedentary lifestyle, unhealthy diets with high levels of fat and sugar, which lead to the formation of advanced glycation end products and unbalanced gut microbiota composition [29-32]. Furthermore, amputees with physical disabilities and inactive lifestyles are at higher risk of obesity and related metabolic disorders. However, the present study has not evaluated the dietary intake of participants which is an effective factor in MetS.

Logestic regression findings in this study showed no significant association between HRQOL scores and MetS in amputees even after adjustment for age, weight

Table 4 Odds ratio and 95\% confidence interval for MetS across quartile categories of the HRQOL scores

\begin{tabular}{|c|c|c|c|c|}
\hline \multirow[t]{2}{*}{ Quartiles of HRQOL scores } & \multicolumn{2}{|c|}{ Model 1} & \multicolumn{2}{|c|}{ Model 2} \\
\hline & $\overline{\mathrm{OR}}$ & $95 \% \mathrm{Cl}$ & $\overline{\mathrm{OR}}$ & $95 \% \mathrm{Cl}$ \\
\hline \multicolumn{5}{|l|}{ Physical component scale } \\
\hline \multicolumn{5}{|l|}{ Q1(reference) } \\
\hline Q2 & 0.90 & $0.43-1.91$ & 1.25 & $0.53-2.98$ \\
\hline Q3 & 0.92 & $0.43-1.95$ & 1.34 & $0.56-3.20$ \\
\hline Q4 & 1.08 & $0.51-2.27$ & 1.25 & $0.52-2.98$ \\
\hline
\end{tabular}

Mental component scale

Q1(reference)

\begin{tabular}{lllll} 
Q2 & 1.12 & $0.54-2.32$ & 1.31 & $0.55-3.13$ \\
Q3 & 1.79 & $0.84-3.82$ & 1.22 & $0.52-2.85$ \\
Q4 & 1.43 & $0.68-2.99$ & 0.85 & $0.35-2.01$ \\
\hline
\end{tabular}

Model 1: Unadjusted logistic regression model

Model 2: Logistic regression model with adjustment for age, weight without prosthesis, physical activity, smoking status and additional war-related injuries 
without prosthesis, physical activity, smoking status and additional war-related injuries. It seems that other factors such as sedentary life style are more effective in weight and related metabolic abnormalities than the quality of life in this group of individuals $[9,10]$. In previous studies poorer HRQOL in lower limb amputees have been revealed in comparison with general population [3, 33-35]. Indeed, physical inactivity caused by amputation could affect the quality of life in amputees. However, there are limited studies concerning the evaluation of HRQOL in amputees according to their metabolic disorders. Different factors including pain, depression, social supports, prosthesis problems and social activity participation may have effect on HRQOL in amputees [3, 36]. The relatively no association between Mets and HRQOL is found in veterans with bilateral lower limb amputations. Therefore, we conclude that although having the major disabily could be strong enough to cause poor quality of life [3], poor quality of life alone could not be associated with health burden in this population. The association of metabolic abnormalities with HRQOL has been assessed in previous studies. Jahangiri et al. demonstrated negative relationship between HRQOL and MetS. They declared that abdominal obesity and high blood pressure are associated with lower HRQOL in the participants with MetS [12]. Tsai et al. revealed that participants with MetS had lower scores on physical function and general health [37]. Porter et al. showed that obesity, diabetes, vascular disease, and heart diseases were significantly related with low HRQOL [38]. However, some studies reported no significant changes in HRQOL in individuals with metabolic abnormalities. Lopez-Garcia et al. in a study evaluated the HRQOL in normal-weight and obese individuals with or without metabolic abnormalities and revealed that compared to healthy normalweight subjects, the metabolically unhealthy normalweight and the healthy obese individuals had a similar HRQOL [39]. The other study in Iran that used the different questionnaire for evaluating quality of life reported no association between quality of life factors and MetS in men [40]. Therefore the association between MetS and HRQOL is still under investigation and more detailed studies are recommended especially in veterans with bilateral lower amputation as a group with high prevalence of MetS in order to decide compensation policies. There are some limitations in this study. It was conducted on a part of veterans with bilateral lower amputation and the results are not representative of the population as a whole and cannot be generalized. Moreover, due to the cross-sectional nature of this study, no causality could be found between bilateral lower limb amputation and MetS. Besides, no comparison with non-veterans amputees or healthy population as control groups, was conducted. So, further long-term studies with the aim of assessing the effect of HRQOL on MetS in this group of veterans are suggested.

\section{Conclusion}

In conclusion, our findings reveal a high prevalence of MetS and low HRQOL in veterans with bilateral lower amputation. Although there was no significant difference in HRQOL between subjects with Mets and those without MetS, close monitoring of these patients for concomitant diseases such as diabetes mellitus and heart diseases and improving their HRQOL by using effective method is necessary.

\section{Abbreviations}

ATP III: Adult treatment panel III; BUN: Blood urea nitrogen; HRQOL: Healthrelated quality of life; MetS: Metabolic syndrome; SGOT: Serum glutamate oxaloacetate transaminase; SGPT: Serum glutamate pyruvate transaminase; VMAF: Veterans and martyrs affairs foundation

\section{Acknowledgements}

The authors acknowledge veterans, Veterans and Martyrs Affairs Foundation (VMAF) and Janbazan medical and engineering research center (JMERC) for their valuable helps and funding.

\section{Funding}

Janbazan medical and engineering research center (JMERC).

Availability of data and materials

The datasets analysed during the current study are available from the corresponding author on reasonable request.

\section{Authors' contributions}

HE designed the study, performed the statistical analysis and drafted the manuscript. MS designed the study. SH designed the study. PA helped to draft the manuscript. BM designed the study, helped to draft the manuscript. MM, FE and MS carried out the study. All authors read and approved the final manuscript.

\section{Competing interests}

The authors declare that they have no competing interests.

\section{Consent for publication}

Not applicable.

\section{Ethics approval and consent to participate}

The ethics committee of Janbazan medical and engineering research center (JMERC) approved the study (No. 85-E-P-102, date of approval: November 29, 2006) and written informed consents were obtained from all veterans.

\section{Publisher's Note}

Springer Nature remains neutral with regard to jurisdictional claims in published maps and institutional affiliations.

\section{Author details}

${ }^{1}$ Obesity and Eating Habits Research Center, Endocrinology and Metabolism Molecular -Cellular Sciences Institute, Tehran University of Medical Sciences,

Tehran, Iran. ${ }^{2}$ Janbazan Medical and Engineering Research Center (JMERC),

Tehran, Iran. ${ }^{3}$ Endocrinology and Metabolism Research Center, Endocrinology and Metabolism Clinical Sciences Institute, Tehran University of Medical Sciences, Tehran, Iran. ${ }^{4}$ Prevention Department, Janbazan Medical and Engineering Research Center (JMERC), No.17, Farokh st, Moghadas Ardebili st, Yaman st, Chamran Ave, Tehran, Iran. ${ }^{5}$ Endocrine and Metabolic Research Center, Shiraz University of Medical Science, Namazi Hospital, Shiraz, Iran. 
Received: 5 October 2016 Accepted: 26 March 2017

\section{Published online: 05 April 2017}

\section{References}

1. Babiæ-Banaszak A, Kovaèiæ L, Kovaèeviæ L, Vuletiæ G, Mujkiæ A, Ebling Z. Impact of war on health related quality of life in Croatia: population study. Croat Med J. 2002:43(4):396-402.

2. Soroush A, Falahati F, Zargar M, Soroush M, Khateri S, Khaji A. Amputations due to landmine and unexploded ordnances in post-war Iran. Arch Iran Med. 2008;11(6):595-7.

3. Rahimi A, Mousavi B, Soroush M, Masumi M, Montazeri A. Pain and healthrelated quality of life in war veterans with bilateral lower limb amputations. Trauma Mon. 2012;17(2):282-6.

4. Ebrahimzadeh MH, Rajabi MT. Long-term outcomes of patients undergoing war-related amputations of the foot and ankle. J Foot Ankle Surg. 2007; 46(6):429-33.

5. Ebrahimzadeh MH, Moradi A, Khorasani MR, Hallaj-Moghaddam M, Kachooe AR. Long-term clinical outcomes of war-related bilateral lower extremities amputations. Injury. 2015;46(2):275-81.

6. Rahimi A, Masoumi M, Soroush M, Mousavi B. Orthopedic complications in bilateral lower limb amputation. IJOS. 2009;7(2):58-63.

7. Hanley MA, Ehde DM, Jensen M, Czerniecki J, Smith DG, Robinson LR. Chronic pain associated with upper-limb loss. Am J Phys Med Rehabil. 2009:88(9):742

8. Ebrahimzadeh MH, Moradi A, Bozorgnia S, Hallaj-Moghaddam M. Evaluation of disabilities and activities of daily living of war-related bilateral lower extremity amputees. Prosthet Orthot Int. 2016;40(1):51-7.

9. Rose H, Schweitzer P, Charoenkul V, Schwartz E. Cardiovascular disease risk factors in combat veterans after traumatic leg amputations. Arch Phys Med Rehabil. 1987;68(1):20-3.

10. Kurdibaylo SF. Obesity and metabolic disorders in adults with lower limb amputation. J Rehabil Res Dev. 1996;33(4):387

11. Program NCE. Expert Panel on Detection, Evaluation, and Treatment of High Blood Cholesterol in Adults (Adult Treatment Panel III): Third Report of the National Cholesterol Education Program (NCEP) Expert Panel on Detection, Evaluation, and Treatment of High Blood Cholesterol in Adults (Adult Treatment Panel III) fi-nal report. Circulation. 2002;106(25):3143-421..

12. Jahangiry L, Shojaeezadeh D, Montazeri A, Najafi M, Mohammad K. Healthrelated Quality of Life Among People Participating in a Metabolic Syndrome E-screening Program: A Web-based Study. Int J Prev Med. 2016;7:27.

13. Slagter SN, van Vliet-Ostaptchouk JV, van Beek AP, Keers JC, Lutgers HL, van der Klauw MM, et al. Health-Related Quality of Life in Relation to Obesity Grade, Type 2 Diabetes, Metabolic Syndrome and Inflammation. PLoS One 2015;10(10):e0140599.

14. Mousavi B, Soroush MR, Montazeri A. Quality of life in chemical warfare survivors with ophthalmologic injuries: the first results form Iran Chemical Warfare Victims Health Assessment Study. Health Qual Life Outcomes. 2009:7:2

15. Dobbelsteyn CJ, Joffres MR, MacLean DR, Flowerdew G. A comparative evaluation of waist circumference, waist-to-hip ratio and body mass index as indicators of cardiovascular risk factors. The Canadian Heart Health Surveys. Int J Obes Relat Metab Disord. 2001:25(5):652-61.

16. Fazizi F, Esmaillzadeh A, Mirmiran FP. Obesity and cardiovascular disease risk factors in Tehran adults: a population-based study. East Mediterr Health J. 2004;10(6):887-97.

17. Grundy SM. Metabolic syndrome pandemic. Arterioscler Thromb Vasc Biol. 2008;28(4):629-36

18. Azizi F, Hadaegh F, Khalili D, Esteghamati A, Hosseinpanah F, Delavari A, et al. Appropriate definition of metabolic syndrome among Iranian adults: report of the Iranian National Committee of Obesity. Arch Iran Med. 2010;13(5):426-8.

19. Ware Jr JE, Kosinski M, Gandek B, Aaronson NK, Apolone G, Bech P, et al. The factor structure of the SF-36 Health Survey in 10 countries: results from the IQOLA Project. International Quality of Life Assessment. J Clin Epidemiol. 1998;51(11):1159-65.

20. Montazeri A, Goshtasebi A, Vahdaninia M, Gandek B. The Short Form Health Survey (SF-36): translation and validation study of the Iranian version. Qual Life Res. 2005;14(3):875-82.

21. Ford ES, Giles WH, Dietz WH. Prevalence of the metabolic syndrome among US adults: findings from the third National Health and Nutrition Examination Survey. JAMA. 2002;287(3):356-9.
22. Maleki F, Sayehmiri K, Sayehmiri F, Kiani F, Nasiri S, Mohhammadi H, Emraii M. Metabolic syndrome prevalence in Iran: a systematic review and meta-analysis. J Kermanshah Univ Med Sci. 2014;18:242-50.

23. Naschitz JE, Lenger R. Why traumatic leg amputees are at increased risk for cardiovascular diseases. QJM. 2008;101(4):251-9.

24. Magalhães P, Capingana DP, Silva AB, Capunge IR, Gonçalves MA. Arterial stiffness in lower limb amputees. Clin Med Insights Circ Respir Pulm Med. 2011;5:49-56.

25. Won KB, Chang HJ, Hong SJ, Ko YG, Hong MK, Jang Y, et al. Prognostic usefulness of metabolic syndrome compared with diabetes in Korean patients with critical lower limb ischemia treated with percutaneous transluminal angioplasty. Yonsei Med J. 2014;55(1):46-52.

26. Estirado E, Lahoz C, Laguna F, Garcia-Iglesias F, Gonzalez-Alegre MT, Mostaza JM. Metabolic syndrome in patients with peripheral arterial disease. Rev Clin Esp. 2014:214(8):437-44.

27. Peles E, Akselrod S, Goldstein DS, Nitzan H, Azaria M, Almog S, et al. Insulin resistance and autonomic function in traumatic lower limb amputees. Clin Auton Res. 1995;5:279-88.

28. Modan M, Peles E, Halkin H, Nitzan H, Azaria M, Gitel S, et al. Increased cardiovascular disease mortality rates in traumatic lower limb amputees. Am J Cardiol. 1998;82(10):1242-7.

29. Ejtahed HS, Bahadoran Z, Mirmiran P, Azizi F. Sugar-Sweetened Beverage Consumption Is Associated with Metabolic Syndrome in Iranian Adults: Tehran Lipid and Glucose Study. Endocrinol Metab (Seoul). 2015;30(3):334-42.

30. Angoorani P, Ejtahed HS, Mirmiran P, Mirzaei S, Azizi F. Dietary consumption of advanced glycation end products and risk of metabolic syndrome. Int J Food Sci Nutr. 2016;67(2):170-6.

31. Ejtahed HS, Soroush AR, Angoorani P, Larijani B, Hasani-Ranjbar S. Gut Microbiota as a Target in the Pathogenesis of Metabolic Disorders: A New Approach to Novel Therapeutic Agents. Horm Metab Res. 2016;48(6):349-58.

32. Fallah MS, Sedaghatikhayat B, Guity K, Akbari F, Azizi F, Daneshpour MS. The Relation between Metabolic Syndrome Risk Factors and Genetic Variations of Apolipoprotein V in Relation with Serum Triglyceride and HDL-C Level. Arch Iran Med. 2016;19(1):46-50.

33. Taghipour H, Moharamzad Y, Mafi AR, Amini A, Naghizadeh MM, Soroush MR, et al. Quality of life among veterans with war-related unilateral lower extremity amputation: a long-term survey in a prosthesis center in Iran. J Orthop Trauma. 2009;23:525-30.

34. Hagberg K, Branemark R. Consequences of non-vascular trans-femoral amputation: a survey of quality of life, prosthetic use and problems. Prosthet Orthot Int. 2001:25(3):186-94.

35. van der Schans CP, Geertzen JH, Schoppen T, Dijkstra PU. Phantom pain and health-related quality of life in lower limb amputees. J Pain Symptom Manage. 2002;24(4):429-36.

36. Asano M, Rushton P, Miller WC, Deathe BA. Predictors of quality of life among individuals who have a lower limb amputation. Prosthet Orthot Int. 2008;32(2):231-43

37. Tsai AG, Wadden TA, Sarwer DB, Berkowitz RI, Womble LG, Hesson LA, et al. Metabolic syndrome and health-related quality of life in obese individuals seeking weight reduction. Obesity. 2008;16(1):59-63.

38. Porter AC, Lash JP, Xie D, Pan Q, DeLuca J, Kanthety R, et al. Predictors and Outcomes of Health-Related Quality of Life in Adults with CKD. Clin J Am Soc Nephrol. 2016:11(7):1154-62

39. Lopez-Garcia E, Guallar-Castillon P, Garcia-Esquinas E, Rodriguez-Artalejo F. Metabolically healthy obesity and health-related quality of life: A prospective cohort study. Clin Nutr. 2016. doi:10.1016/j.clnu.2016.04.028.

40. Sarrafzadegan N, Gharipour M, Ramezani MA, Rabiei K, Zolfaghar B, Tavassoli AA, et al. Metabolic syndrome and health-related quality of life in Iranian population. J Res Med Sci. 2011:16(3):254-61. 